\title{
Research Square \\ Identification of a Two-Component System Important for Cell Division of the Rice Pathogen Burkholderia glumae in Response to Nutrient Conditions
}

\author{
Joan Marunga \\ Seoul National University \\ Eunhye Goo \\ Seoul National University \\ Yongsung Kang \\ Seoul National University \\ Ingyu Hwang ( $\square$ ingyu@snu.ac.kr) \\ Seoul National University
}

\section{Research Article}

Keywords: Burkholderia glumae, two-component regulatory system, cell division

Posted Date: February 16th, 2021

DOI: https://doi.org/10.21203/rs.3.rs-198917/v1

License: (c) (i) This work is licensed under a Creative Commons Attribution 4.0 International License.

Read Full License 


\section{Abstract}

Bacterial two-component regulatory systems control the expression of sets of genes to coordinate physiological functions in response to environmental cues. Here, we report that a genetically linked but functionally unpaired two-component system comprising the sensor kinase GluS (BGLU_1G13350) and the response regulator GluR (BGLU_1G13360) is critical for cell division in the rice pathogen Burkholderia glumae BGR1. The gluR null mutant, unlike the gluS mutant, formed filamentous cells in Luria-Bertani medium and was sensitive to exposure to $42^{\circ} \mathrm{C}$. Expression of genes responsible for cell division and cellwall $(d c w)$ biosynthesis in the gluR mutant was elevated compared to the wild type, resulting in an imbalance between FtsZ and FtsA. GluR-His bound to the putative promoter regions of ftsA and ftsZ, indicating that repression of genes in the $d c w$ cluster by GluR is critical for cell division in B. glumae. The gluR mutant did not form filamentous cells in M9 minimal medium, whereas exogenous addition of glutamine or glutamate to the medium induced filamentous cell formation. These results implicate glutamine and glutamate as external stimuli that modulate GluR-mediated cell division in B. glumae. Therefore, GluR controls cell division of B. glumae in a nutrition-dependent manner.

\section{Introduction}

Two-component systems (TCS) consisting of a sensor kinase and a cognate response regulator are common in bacteria ${ }^{1}$. They are essential for the responses of bacteria to changes in environmental factors such as $\mathrm{pH}$, osmotic pressure, antibiotics, and quorum-sensing (QS) signals ${ }^{1}$. The sensor kinases are autophosphorylated after sensing an environmental stimulus, which is followed by phosphotransfer from the phosphorylated sensor kinases to the response regulators ${ }^{1}$. The phosphorylated response regulators then undergo conformational changes to become active, thereby controlling the expression of target genes ${ }^{1}$. The genes encoding sensor kinases and response regulators are often genetically linked in bacterial genomes and functionally paired ${ }^{2,3}$. In addition to paired TCSs, sensor kinases and transcriptional regulators can crosstalk, thus modulating multiple biological processes in response to environmental signals irrespective of their genetic linkage $\mathrm{e}^{2,4-6}$.

We study the social behavior and host interactions of the rice bacterial pathogen Burkholderia glumae, the cause of rice panicle blight ${ }^{7,8}$. A phytotoxin, toxoflavin, is the major virulence factor of B. glumae and exerts a toxic effect on photosynthetic organisms by generating radicals under light ${ }^{8,9}$. The virulencefactor biosynthesis and motility of $B$. glumae are dependent on $Q S^{8,10}$. As well as QS, we are interested in TCSs in B. glumae BGR1 because they coordinate and regulate the expression of genes critical for adaptation to stress, survival, fitness in the host, and virulence ${ }^{11-17}$. For instance, CpxAR of Actinobacillus pleuropneumoniae ${ }^{14}, \mathrm{ArcAB}$ of Escherichia coli ${ }^{15}$, and $\mathrm{KdpDE}^{16}$ and $\mathrm{PhoPQ}^{17}$ in a variety of bacterial taxa reportedly promote growth, fitness, and survival in the host. In addition, AgrAC, SsrAB, SaeRS, and ArlRS of Staphylococcus aureus and BvgAS of Bordetella pertussis are necessary for virulence $^{11-13}$. Few studies have focused on TCSs in $B$. glumae, probably because of concern over 
repeating works on other pathogens. However, Karki et al. reported that the PidS/PidR TCS is essential for the pigmentation and virulence of $B$. glumae $411 \mathrm{gr}-6^{18}$.

In this study, we identified a TCS composed of the sensor kinase GluS and the response regulator GluR, which was critical for normal cell division in B. glumae BGR1. gluR and gluS were cotranscribed, but GluR functioned independently of GluS in normal cell division. We report that GluR regulates the gene cluster involved in cell division and cell wall ( $d c w)$ biosynthesis to maintain balanced expression of FtsZ and FtsA for normal septum formation ${ }^{19}$. We conclude that external nutritional conditions modulate cell division in a TCS-dependent manner in B. glumae. These findings provide insight into how the recognition of external signals by TCS affects the sophisticated molecular mechanisms involved in controlling bacterial cell division.

\section{Results}

Identification of a TCS critical for normal cell division of B. glumae BGR1. To identify a key TCS important for normal cell division of B. glumae BGR1, we first mutagenized it with mini-Tn 5 and examined the morphology of the mutants. The mutant RT271 formed filamentous cells when grown in Luria-Bertani medium (LB) (Fig. 1a). To determine the insertion site of mini-Tn 5 in the RT271 mutant, a mini-Tn 5 insertion along with flanking sequences was rescued by digestion of its genomic DNA with EcoRI, self-ligation, and transformation into E. coli DH5a. Flanking sequences of mini-Tn 5 from the rescued plasmid pRT271E revealed that an annotated gene BGLU_1G13360 had an insertional mutation (Fig. 1b). This gene, gluR, encoded a $27.7 \mathrm{kDa}$ protein that exhibited $99.6 \%$ similarity to known OmpR-type response regulators such as BURPS305_7006 in B. pseudomallei 305, RisA (BMA10247_1253) in $B$. mallei NCTC 10247, and BCENMC03_1962 of B. cenocepacia MCO-3 (Supplementary Fig. S1a). Downstream of gluR was a putative sensor kinase, gluS (BGLU_1G13350), (Fig. 1b) that showed 96.7, 94.1, and 90.0\% identities with known sensor kinases such as Envz1 (BGL_1C23830) in B. plantarii, BGLA_1G24110 in B. gladioli BSR3, and RisS (BMA1486) in B. mallei ATCC 23344, respectively (Supplementary Fig. S1b).

Due to the proximity of gluS and gluR in the BGR1 genome, we reasoned that these two genes might be co-transcribed into a polycistronic RNA. Therefore, we performed reverse transcription-polymerase chain reaction (RT-PCR) with specific primers (Fig. 1b). We found that gluR and gluS were indeed co-transcribed (Fig. 1C). We next mutagenized pBGH1, a cosmid carrying gluS and gluR, with Tn3-gusA to generate mutants of gluR and gluS followed by marker-exchange into B. glumae BGR1, resulting in BGLUR133 (BGR1 gluR::Tn 3-gusA133) and BGLUS35 (BGR1 gluS::Tn3-gusA35) (Fig. 1b). Although gluR and gluS were co-transcribed, the insertion of Tn $3 g u s A 133$ in gluR did not cause a polar effect (Fig. 1d).

Aberrant cell division due to a mutation in gluR. To determine whether the insertion of Tn3-gusA in gluR or gluS conferred a similar cell morphology to the RT217 mutant, we observed the morphology of the gluR and gluS mutants under a light microscope. The gluR mutant BGLUR133 showed extensive filamentous cells in LB medium (Fig. 2), consistent with the initial phenotype of the gluR::min-Tn 5 mutant RT271 in LB 
(Fig. 1a). However, the gluS mutant BGLUS35 formed normal cells in LB medium (Fig. 2). The gluR mutant BGLUR133 maintained a normal rod-shaped cell morphology similar to that of the gluSmutant BGLUS35 in M9 minimal medium (Fig. 2). Transmission electron microscopy (TEM) of ultrathin sections of the gluR mutant BGLUR133 revealed characteristic features of filamentous cells with multiple nuclei and indents along the cell membrane at points where the septum would have formed to separate dividing cells (Fig. 3a). The genetically complemented strain of the gluR mutant BGLUR133 with pBGH13, BGLUR133C, had morphologically uniform rod-shaped cells (Fig. 3a). The growth of the gluR mutant BGLUR133 and the wild-type BGR1 for 30 hours in LB medium was similar (Supplementary Fig. S2, Fig. 3b). Although filamentous cells of the gluR mutant BGLUR133 remained viable for 30 hours, their abundance decreased after 18 hours (Fig. 3b).

Direct control of genes involved in cell division by GluR. Because TEM suggested the involvement of GluR in cell division, we determined whether GluR influences the expression of genes in the dcw cluster involved in cell division. In B. glumae, there were 15 annotated genes; e.g., ftsA, ftsl, ftsL, ftsQ, ftsW, and $f t s Z$ in the $d c w$ cluster and $f t s B$ and $f t s K$ in other regions (Fig. 4a, b). The expression levels of $f t s A$, ftsB, $\mathrm{ftsl}, \mathrm{ftsK}, \mathrm{ftsL}, \mathrm{fts} Q \mathrm{fts} W$, and $\mathrm{fts} Z$ in the gluR mutant BGLUR133 were significantly increased compared to those in the wild-type BGR1 (Fig. 4c). The expression levels of the eight genes in BGLUR133C were similar to those in the wild type (Fig. 4c). To determine whether GluR directly controls their expression, we performed electrophoretic mobility shift assays (EMSA) on the putative promoter regions of ftsA and ftsZ and purified His-tagged GluR (GluR-His). The binding of GluR-His to the putative promoter regions of ftsA and $f t s Z$ confirmed that GluR-His directly represses the expression of cell division genes in B. glumae (Fig. 4d).

\section{Alleviation of aberrant cell morphology by constitutive expression of ftsA in the gluR mutant BGLUR133.}

Because the FtsA to FtsZ ratio is critical for normal bacterial cell division, we evaluated the role of GluR in its maintenance. Taking the expression levels of $f t s A$ and $f t s Z$ in the wild type as 1.00 , the expression levels of these two genes were 1.21 and 1.67, respectively, in the gluR mutant BGLUR133 (Fig. 4c). To confirm that imbalanced expression of $f t s A$ and $f t s Z$ causes abnormal cell division, we constitutively expressed ftsA under the control of the trc promoter in the wild type, the gluR mutant BGLUR133, and the complemented strain BGLUR133C; the resulting strains were designated BGR1(pFtsA), BGLUR133(pFtsA), and BGLUR133C(pFtsA), respectively. Cells of BGLUR133(pFtsA) showed normal cell division as well as a 5.2 fold increase in ftsA expression (Fig. 5). Moreover, ftsA expression was increased more than 100 fold in BGR1 (pFtsA) and BGLUR133C(pFtsA), whose cells underwent abnormal division (Fig. 5).

Influence of glutamate and glutamine on GluR-mediated control of cell division. Because the gluR mutant BGLUR133 formed filamentous cells in LB medium but not in M9 minimal medium, we reasoned that the amino acids in LB medium might be the cause of filamentous cell formation. Therefore, we added $10 \%$ casamino acids to M9 minimal medium to evaluate their influence on the morphology of the gluR mutant BGLUR133. Adding casamino acids to M9 minimal medium transformed the morphologically normal cells of the gluR mutant BGLUR133 into filamentous cells (Fig. 6). To identify the amino acid(s) responsible for triggering filamentous cells in the gluR mutant BGLUR133, 20 amino acids were 
individually added to M9 minimal medium. Of the 20 amino acids, only glutamine and glutamate individually or in combination triggered cells of the gluR mutant BGLUR133 to become filamentous in M9 minimal medium (Fig. 7a, b, c). When 13 amino acids excluding glutamine and its six amino-acid metabolites (glutamate, serine, alanine, proline, aspartate, and asparagine) were added to M9 minimal medium, the gluR mutant BGLUR133 maintained a normal morphology (Fig. 7d). These results confirmed the role of glutamine in the gluR-mediated control of cell division in B. glumae.

Because environmental glutamine and glutamate affected the cell morphology of the gluR mutant BGLUR133 in M9 minimal medium, we examined the expression levels of seven fts genes in M9 minimal medium with or without glutamine and glutamate. The expression levels of the seven $\mathrm{fts}$ genes were significantly lower in the gluR mutant BGLUR133 than in the wild type or the BGLUR133C complemented strain (Fig. 7e). However, addition of glutamine to M9 minimal medium increased the expression levels of the seven fts genes in the gluR mutant BGLUR133 (Fig. 7f).

Heat sensitivity due to an imbalance of FtsA and FtsZ in the gluR mutant. Because fts genes were identified in a temperature-sensitive filamenting mutant, we assessed whether the filamenting gluR mutant BGLUR133 is heat sensitive. The number of cells of the gluR mutant BGLUR133 decreased significantly after 6 hours at $42^{\circ} \mathrm{C}$ and they were entirely nonviable after 12 hours in LB medium (Fig. 8a). The wild-type BGR1, the gluS mutant BGLUS35, and the complemented strain BGLUR133C showed no growth but prolonged survival at $42^{\circ} \mathrm{C}$ (Fig. 8a). In M9 minimal medium at $42^{\circ} \mathrm{C}$, the gluR mutant BGLUR133 mutant retained viability for 18 hours and subsequently lost viability (Fig. 8b). By contrast, the wild-type BGR1 and the complemented strain BGLUR133C increased in cell number during the static period of gluR mutant BGLUR133 in M9 medium (Fig. 8b).

\section{Discussion}

In addition to QS systems, pathogens likely manipulate environmental factors. Here we investigated the response regulator, GluR, which is crucial for normal cell division in B. glumae. Although gluR and gluS were co-transcribed, GluS was not the counterpart of GluR because a mutation in gluS did not affect normal cell division of $B$. glumae. Such a genetically linked but functionally independent TCS system was reported for risS and risA, which encode a sensor kinase and a response regulator, respectively, in $B$. pertussisi ${ }^{3}$. risS and risA were genetically linked but functionally independent ${ }^{3}$. Phosphorylation of RisA was mediated by crosstalk with a distant histidine kinase, RisK ${ }^{4}$. Therefore, an as-yet-unidentified sensor kinase may be responsible for phosphorylation of GluR in B. glumae.

Cell division involves ingrowth of the cell wall and membrane and septum formation in the chromosome of rod-shaped bacteria such as $B$. gluma $e^{20}$. To ensure equal partitioning of chromosomes into daughter cells, the expression of genes involved in cell division must be properly regulated ${ }^{19,20}$. In most bacteria, cell division and cell-wall synthesis are regulated by a series of genes in the $d c w$ cluster $^{19}$. Within bacterial groups of the same taxon and cell shape, the order and regulation of genes in the $d c w$ cluster are highly conserved ${ }^{21}$. Therefore, it was not surprising that in B. glumae, the $d c w$ cluster displayed 
significant similarities to that of $E$. coli ${ }^{22}$. Pioneer studies of the $d c w$ cluster genes in $E$. coli spotlighted $f t s Z$ as the key element in cell division ${ }^{23,24}$. It was later noted that FtsZ is not sufficient to drive septation, leading to discovery of, for instance, $f t s A, f t s Q$, and $f t s{ }^{22}$.

The mechanisms of regulation of the $d c w$ cluster are unclear, despite the presence therein of several regulatory elements, e.g., internal promoters, transcript stabilizers, and protein ratios ${ }^{22,25}$. Studies on the control of cell division have concentrated on FtsZ. Multiple promoter regions have been reported upstream of $f t s Z$ in the $d c w$ cluster, indicating regulation at the transcriptional level ${ }^{22,25,26}$. We found that GluR binds to the upstream promoter regions of $f t s Z$ and $f t s A$ located in the $f t s A$ and $f t s Q$ coding regions, respectively. Unlike positive regulators in $E$. coli, such as $\mathrm{Sdi}^{27}{ }^{27}$, the phase-specific sigma factor $^{28}$, and $\mathrm{RcsB}^{29}$, GluR negatively regulates cell division in $B$. glumae.

In the $d c w$ cluster, biased expression of genes resulting from a mutation in gluR induced aberrant cell division. The GluR-controlled expression of $d c w$ cluster genes was essential for normal cell division in $B$. glumae. FtsZ may be tethered to the membrane by two cytoplasmic membrane-associated proteins, ZipA and $\mathrm{Fts}^{30}{ }^{30}$, thus mediating cell division. Each $E$. coli cell is estimated to contain $3000-5000$ molecules of FtsZ, 50-200 of FtsA, and 1500 of ZipA ${ }^{31}$. In addition, an imbalanced FtsZ and FtsA ratio is detrimental to $E$. coli ${ }^{19,32}$. In the filamentous cell-forming gluR mutant, expression of $f t s Z$ was higher than that of $f t s A$, but the constitutive expression of $f t s A$ restored a filamentous morphology. Although the optimal FtsZ and FtsA ratio is unknown, a 5.2fold increase in $\mathrm{fts} A$ expression in the gluR mutant restored normal cell division to filamentous cells.

Because LB medium is rich in amino acids, and filamentation of the gluR mutant was facilitated by supplementation of extracellular glutamine or glutamate in $M 9$, the glutamine- and glutamate-dependent filamentous cell formation at an early stage of growth in LB was explicable. However, the number of filamentous cells of the gluR mutant BGLUR133 decreased over time, possibly as a result of depletion of amino acids, including glutamine and glutamate, 12 hours after incubation (Supplementary Fig. S3). Because the gluR mutant formed filamentous cells in a glutamine or glutamate-dependent manner, we hypothesized that GluR phosphorylation is caused by extracellular glutamine or glutamate, which promotes proper cell division by repressing $d c w$ cluster genes. Extracellular glutamine and glutamate reportedly alter the expression of genes involved in cell division and cell-wall synthesis of $B$. subtilis ${ }^{33}$. Beuria et al. reported that an increased FtsZ polymerization rate and extent in $E$. coli resulted from extracellular glutamine ${ }^{34}$. It was noted that FtsZ showed optimal polymerization as large, bundled filamentous structures in E. coli in the presence of $1 \mathrm{M}$ glutamine $^{34}$. Interestingly, FtsZ polymers formed in the absence of glutamine were ninefold less stable than those in its presence, emphasizing the roles of these amino acids in the stability of FtsZ polymers ${ }^{34}$.

Connections between TCS and glutamine metabolism have been reported in other bacterial taxa. For example, GInK-GInL of Bacillus subtlis ${ }^{35}$, GluR-GluK of Streptomyces coelicolor ${ }^{36}$, and AauR-AauS of Pseudomonas putida ${ }^{37}$ reportedly sense and control glutamate uptake. In other bacteria, the TCSs 
involved in glutamine sensing and uptake are located close to the glutamine $A B C$ transporter ${ }^{35-37}$. GluR is not likely to be involved in glutamine uptake because we reported that Gltl is responsible for glutamine uptake in B. glumae ${ }^{38}$. A bona fide sensor kinase responsible for glutamine sensing and GluR phosphorylation is yet to be identified in $B$. glumae.

The fact that the gluR mutant BGLUR133 was sensitive to heat treatment at $42^{\circ} \mathrm{C}$ was somewhat expected because the name $f t s$ was coined from filamentous temperature sensitive mutants in $E$. col ${ }^{39}$. Mutations in septation genes conferred an elongated morphology on $E$. coli; similarly, filamentous $B$. glumae caused by a gluR mutation were heat sensitive. This supports the hypothesis that GluR is crucial for cell division and an optimum gene expression profile. Taken together, our findings indicate that GluR is key for maintaining the gene expression profile required for glutamine- or glutamate-dependent control of cell division in B. glumae BGR1.

\section{Materials And Methods}

Bacterial strains and growth conditions. The bacterial strains and plasmids used are listed in Supplementary Table S1. Unless stated, the strains were grown in LB medium containing $0.1 \%(\mathrm{w} / \mathrm{v})$ tryptone, $0.5 \%(\mathrm{w} / \mathrm{v})$ yeast extract, $0.5 \%(\mathrm{w} / \mathrm{v})$ sodium chloride, and $1.5 \%$ agar as required (Affymetrix ${ }^{\circledR}$, Cleveland, $\mathrm{OH}$ ) with the appropriate antibiotics at $37^{\circ} \mathrm{C}$. Antibiotics were used at the following concentrations: rifampicin, $100 \mu \mathrm{g} / \mathrm{mL}$; ampicillin, $50 \mu \mathrm{g} / \mathrm{mL}$; tetracycline, $10 \mu \mathrm{g} / \mathrm{mL}$; kanamycin, 25 and $50 \mu \mathrm{g} / \mathrm{mL}$; and spectinomycin, $50 \mu \mathrm{g} / \mathrm{mL}$. 5-Bromo-4-chloro-3-indoyl- $\beta$-D-galactopyranoside (X-gal) was added at $40 \mu \mathrm{g} / \mathrm{mL}$ as necessary.

DNA manipulation and sequencing. Basic DNA manipulation was conducted following standard protocols ${ }^{40}$. Plasmid DNA from E. coli was isolated using the Biomedic ${ }^{\circledR}$ Plasmid DNA Miniprep Kit (Ibiomedic, Korea) following the manufacturer's instructions. DNA sequencing was performed by Macrogen, Inc. (Seoul, Korea). The genetic information and gene IDs for DNA construction were obtained from the B. glumae BGR1 genome database (GenBank accession numbers: CP001503-CP001508; kropbase.snu.as.kr/cgi_bg.cg). A cosmid library of B. glumae BGR1 was constructed as described previously ${ }^{8}$.

Rescue mini-Tn5, Tn3-gusA, and marker-exchange mutagenesis. Using E. coli S17-1 (pRescue mini-Tn5), random mutations were created in $B$. glumae BGR1 as described previously ${ }^{41}$. Successful mutants were isolated by selection on LB agar containing kanamycin. The rescued $\operatorname{mini}$ Tn 5 mutants were screened for phenotypic changes. Following a previous method ${ }^{42}$, the flanking regions were sequenced using the 0 end primer (5'-GGTTTTCACCGTCATCACCG-3'), and the TCS genes were disrupted using the identified rescue mini-Tn 5 insertions.

The pLAFR3 derivatives of pBGH1 carrying gluR (BGLU_1G13360) and gluS (BGLU_1G13350) were mutagenized using Tn3-gusA as described previously ${ }^{43}$. The Tn3-gusA insertion site and orientation in each mutant were mapped by restriction enzyme digestion analysis, and the plasmid sequenced using 
the Tn3gus primer (5'-CCGGTCATCTGAGACCATTAAAAGA-3'). The plasmids carrying Tn3-gusA insertions were marker-exchanged into $B$. glumae BGR1 via tri-parental mating ${ }^{44}$ to generate BGLUR133 and BGLUS35. All marker-exchange mutants were confirmed by southern hybridization analysis.

Bacterial growth and viability assay. Overnight liquid cultures of the $B$. glumae strains were adjusted to an $\mathrm{OD}_{600}$ of 0.05 and subcultured into fresh LB medium. The cultures were incubated for 30 hours at $37^{\circ} \mathrm{C}$ with shaking at $250 \mathrm{rpm}$. At 6hour intervals, bacterial growth was assayed by spotting $10 \mu \mathrm{L}$ of serial dilutions in triplicate on LB agar plates. Bacterial growth was expressed as $\log \mathrm{CFU} / \mathrm{mL}$ after 2 days of incubation at $37^{\circ} \mathrm{C}$.

Cell viability was assayed using the LIVE/DEAD BacLight ${ }^{\text {TM }}$ Bacterial Viability Kit, which contains SYTO® 9 green-fluorescent nucleic acid stain and the red-fluorescent nucleic acid stain, propidium iodide (Invitrogen ${ }^{T M}$, Carlsbad, CA), following the manufacturer's instructions. Fluorescence images were captured using a confocal laser scanning microscope (Leica SP8X, Wetzlar, Germany) at excitation/emission wavelengths of 483/490-540 and 535/890-680 nm for green and red fluorescence, respectively.

Transmission electron microscopy. Bacterial cells were harvested from overnight cultures and prepared for observation by transmission electron microscopy (TEM) as reported previously ${ }^{38}$. Electron micrographs were acquired using a JEM 1010 microscope (JEOL, Tokyo, Japan) with acceleration voltages of 180 and $100 \mathrm{kV}$ from a LIBRA 120 energy-filtration microscope (Carl Zeiss, Oberkochen, Germany).

Quantitative reverse transcription-polymerase chain reaction. Total RNA was isolated from B. glumae BGR1, BGLUR133, and BGLUR133C using the RNeasy ${ }^{\circledR}$ Mini Kit (Qiagen, Hilden, Germany) following the manufacturer's instructions. Genomic DNA was removed using DNase I (Thermo Fisher Scientific, Vilnius, Lithuania). From $1 \mu \mathrm{g}$ of RNA, reverse transcription for CDNA synthesis was performed at $42^{\circ} \mathrm{C}$ for 1 hour with the Recombinant RNasin ${ }^{\circledR}$ Kit (Promega, Madison, WI). Using specific primer sets (Supplementary Table S2), ftsA, ftsB, ftsl, ftsK, ftsL, fts $Q$, fts $W$, and $f t s Z$ cDNAs were synthesized. Transcription levels were determined using SsoFast EvaGreen Supermix (Bio-Rad, Hercules, $\mathrm{CA}$ ) under the following conditions: $95^{\circ} \mathrm{C}$ for 30 seconds followed by 30 cycles of $95^{\circ} \mathrm{C}$ for 5 seconds and $55^{\circ} \mathrm{C}$ for 5 seconds. PCR was performed in triplicate and gene expression values were normalized to that of 16S rRNA using Bio-Rad CFX Manager software.

Constitutive expression of ftsA. To express $\mathrm{fts} A$ under the control of the trc promoter in pKK38, we amplified the ftsA-coding region from the $B$. glumae strains BGR1, BGLUR133, and BGLUR133C using the primers FtsA_Nco1 (5'-GGCCATGGAGCAAAGACTACAAAGATCT-3') and FtsA_HindIII (5'CCAAGCTTTCAGAAATTGCTCAGGAACC-3') and a TaKaRa PCR Kit (TaKaRa Bio Inc., Kusatsu, Shiga, Japan) following the manufacturer's instructions. The PCR fragments were first cloned into the Sma1 sites of pBluescript II SK (+) and transferred to the Nco1-Hindll sites of pKK38 as described previously ${ }^{38}$. By means of tri-parental mating ${ }^{44}$, pKK38 derivatives were conjugated into the respective $B$. glumae 
strains to generate strains with elevated ftsA expression-BGR1(pFtsA), BGLUR133(pFtsA), and BGLUR133C(pFtsA).

Growth and viability of $B$. glumae strains at $42^{\circ} \mathrm{C}$. The $B$. glumae BGR1, TCS null mutants, and BGLUR133C strains were cultured overnight at $37^{\circ} \mathrm{C}$, and the optical density at $600 \mathrm{~nm}\left(\mathrm{OD}_{600}\right)$ was adjusted to 0.05 . The strains were incubated at $42^{\circ} \mathrm{C}$ with shaking at $250 \mathrm{rpm}$ for 24 hours in LB and M9 minimal media, and the cell density was measured at 6hour intervals.

Environmental stimuli driving GluR responses. We cultured the wild type, gluR mutant BGLUR133, and BGLUR133C in M9 minimal medium ( $6 \mathrm{~g}$ of $\mathrm{Na}_{2} \mathrm{HPO}_{4}, 3 \mathrm{~g}$ of $\mathrm{KH}_{2} \mathrm{PO}_{4}, 0.5 \mathrm{~g}$ of $\mathrm{NaCl}$, and $1 \mathrm{~g}$ of $\mathrm{NH}_{4} \mathrm{Cl}$ in 1 $\mathrm{L}$ of deionized water containing $1 \mathrm{mM} \mathrm{MgSO}_{4}$ and $0.1 \mathrm{mM} \mathrm{CaCl}_{2}$ ) supplemented with $0.2 \%$ glucose. To evaluate whether amino acids are required for GluR activity, M9 minimal medium was supplemented with 10\% Bacto $^{\text {TM }}$ Casamino Acids (Becton, Dickson \& Co., Franklin Lakes, $\mathrm{NJ}$ ) that comprises 20 essential amino acids. Individual amino acids (Sigma Aldrich ${ }^{\text {TM }}$, St. Louis, MI) were analyzed at the concentrations in LB medium ${ }^{45}$.

Glutamate utilization in B. glumae. Overnight liquid cultures of the wild-type BGR1 were adjusted to an optical density of $\mathrm{OD}_{600}$ of 0.05 and subcultured in $L B$ medium for 24 hours at $37^{\circ} \mathrm{C}$ with shaking at 250 $\mathrm{rpm}$. At 3hour intervals, the cultures were centrifuged $\left(14,000 \mathrm{rpm}, 4^{\circ} \mathrm{C}, 10\right.$ minutes), and the supernatants were collected. Glutamate analysis was carried out by liquid chromatography-mass spectrometry (LCMS2000, Shimadzu, Japan) at the National Instrumentation Center and Environment Management (Seoul National University, Seoul, Korea).

Scanning electron microscopy. B. glumae strains cultured overnight in LB or M9 minimal medium with/without amino acids were harvested, fixed with Karnovsky's fixative [2\% glutaraldehyde, $2 \%$ paraformaldehyde in $0.05 \mathrm{M}$ sodium cacodylate buffer $(\mathrm{pH} 7.4)$ ], and post-fixed with $1 \%$ sodium tetroxide in $0.1 \mathrm{M}$ sodium cacodylate buffer for 1 hour at $4^{\circ} \mathrm{C}$ as described previously ${ }^{46}$. Before imaging, the samples were coated with platinum at $10 \mathrm{~mA}$ for 270 seconds using a G20 lon Sputter Coater (GSEM Co., Suwon, Korea) and electron micrographs were acquired using a Carl Zeiss microscope (Auriga, Zeiss Germany).

Electrophoretic mobility shift assay. GluR-His was purified using an established method ${ }^{10}$. Using the primer set gluR_Nde1/gluR_BamH1 (Supplementary Table S2), we amplified the promoter regions of the putative GluR targets, ftsAp and $f t s Z p$. The resulting PCR products were labeled with biotin using Lightshift Chemiluminescent Electrophoretic Mobility Shift Assay Kits, as described by the manufacturer (Pierce, Appleton, Wisconsin). We used 329 bp upstream of katE1 as a nonspecific competitor DNA amplified using KatE1-F and KatE1-R primers (Supplementary Table S2). Purified GluR-His $(0.75 \mu \mathrm{M})$ was incubated in binding buffer (10 mM Tris-HCl [pH 7.5], $100 \mathrm{mM} \mathrm{NaCl}$, and 5\% [v/v] glycerol) containing 1 $\mathrm{nM}$ biotin-labeled DNA as described previously ${ }^{10}$. For competition assays, unlabeled target DNA at 20 fold molar excess was added to each reaction with the labeled DNA. Using $4 \%(\mathrm{w} / \mathrm{v})$ polyacrylamide gels, the reactions were separated and transferred to nitrocellulose membranes. The bands were detected using 
streptavidin/horseradish peroxidase-derived chemiluminescence kits, as described by the manufacturer (Pierce) and visualized using ChemiDoc XRS + and Image Lab Software (Bio-Rad).

Statistical analysis. All experiments were conducted in triplicate with the appropriate controls. One-way analysis of variance (ANOVA) followed by Tukey's honestly significant difference post hoc analysis in SPSS software (ver. 25 x86-x64; IBM Corp., Armonk, NY) were conducted to detect significant differences. A value of $p<0.05$ was considered indicative of statistical significance.

\section{Declarations}

\section{Acknowledgment}

We thank Woon Jeong Kim and Bongsoo Lee for the generation of gluS and gluR mutants. This work was supported by a National Research Foundation of Korea grant (2020R1F1A1062829) funded by the Ministry of Science and ICT of the Korean government.

\section{Author information}

\section{Affiliations}

${ }^{1}$ Department of Agricultural Biotechnology, Seoul National University, Seoul 08826, Republic of Korea

${ }^{2}$ Research Institute of Agriculture and Life Sciences, Seoul National University, Seoul 08826, Republic of Korea

\section{Joan Marunga ${ }^{1}$, Eunhye Goo ${ }^{1}$, Yongsung Kang ${ }^{1}$, and Ingyu Hwang ${ }^{1,2^{*}}$ \\ Contributions}

Designed the experiments: J.M. and I.H. Performed the experiments: J.M. and E.G. Analyzed the data: J.M., E.G., Y.K., and I.H. Contributed reagents/materials/analysis tools: J.M. and I.H. Wrote the paper: J.M. and I.H.

\section{Competing interests}

The authors declare no competing financial interests.

\section{Corresponding author}

Correspondence to I. Hwang.

\section{References}

1 Gao, R. \& Stock, A. M. Biological insights from structures of two-component proteins. Annu. Rev. Microbiol. 63, 133-154 (2009). 
2 Coutte, L. et al. The multifaceted RisA regulon of Bordetella pertussis. Sci. Rep. 6, 32774;

10.1038/srep32774 (2016).

3 Stenson, T. H., Allen, A. G., Al-Meer, J. A., Maskell, D. \& Peppler, M. S. Bordetella pertussis risA, but not risS, is required for maximal expression of Bvg-repressed genes. Infect. Immun. 73, 5995-6004 (2005).

4 Chen, Q., Ng, V., Warfel, J. M., Merkel, T. J. \& Stibitz, S. Activation of Bvg-repressed genes in Bordetella pertussis by RisA requires cross talk from noncooperonic histidine kinase RisK. J. Bacteriol. 199, e00475-17; 10:1128/JB.00475-17 (2017).

5 Yamamoto, K. et al. Functional characterization in vitro of all two-component signal transduction systems from Escherichia coli. J. Biol. Chem. 280, 1448-1456 (2005).

6 Hellingwerf, K. J. Bacterial observations: a rudimentary form of intelligence? Trends Microbiol. 13, 152-158 (2005).

7 Goo, E., An, J. H., Kang, Y. \& Hwang, I. Control of bacterial metabolism by quorum sensing. Trends Microbiol. 23, 567-576 (2015).

8 Kim, J. et al. Quorum sensing and the LysR-type transcriptional activator ToxR regulate toxoflavin biosynthesis and transport in Burkholderia glumae. Mol. Microbiol. 54, 921-934 (2004).

9 Koh, S. et al. A novel light-dependent selection marker system in plants. Plant Biotechnol. J. 9, 348-358 (2011).

$10 \mathrm{Kim}, \mathrm{J}$. et al. Regulation of polar flagellum genes is mediated by quorum sensing and FlhDC in Burkholderia glumae. Mol. Microbiol. 64, 165-179 (2007).

11 Bronner, S., Monteil, H. \& Prévost, G. Regulation of virulence determinants in Staphylococcus aureus: Complexity and applications. FEMS Microbiol. Rev. 28, 183-200 (2004).

12 Uhl, M. \& Miller, J. Integration of multiple domains in a two-component sensor protein: the Bordetella pertussis BvgAS phosphorelay. EMBO J. 15, 1028-1036 (1996).

13 Perraud, A. L., Kimmel, B., Weiss, V. \& Gross, R. Specificity of the BvgAS and EvgAS phosphorelay is mediated by the C-terminal HPt domains of the sensor proteins. Mol. Microbiol. 27, 875-887 (1998).

14 Yan, K. et al. The CpxAR two-component system contributes to growth, stress resistance, and virulence of Actinobacillus pleuropneumoniae by upregulating wecA transcription. Front. Microbiol. 11, $1026 ; 10.3389 /$ fmicb.01026 (2020).

15 Loui, C., Chang, A. C. \& Lu, S. Role of the ArcAB two-component system in the resistance of Escherichia coli to reactive oxygen stress. BMC Microbiol. 9, 183; 10.1186/147-2180-9-183 (2009). 
16 Freeman, Z. N., Dorus, S. \& Waterfield, N. R. The KdpD/KdpE two-component system: integrating $\mathrm{K}^{+}$homeostasis and virulence. PLoS Pathog. 9, e1003201; 10.1371/journal.ppat.1003201 (2013).

17 Groisman, E. A. The pleiotropic two-component regulatory system PhoP-PhoQ. J. Bacteriol. 183, 1835-1842 (2001).

18 Karki, H. S., Barphagha, I. K. \& Ham, J. H. A conserved two-component regulatory system, PidS/PidR, globally regulates pigmentation and virulence-related phenotypes of Burkholderia glumae. Mol. Plant Pathol. 13, 785-794 (2012).

19 Dai, K. \& Lutkenhaus, J. The proper ratio of FtsZ to FtsA is required for cell division to occur in Escherichia coli. J. Bacteriol. 174, 6145-6151 (1992).

20 Harry, E. Bacterial cell division: Regulating Z-ring formation. Mol. Microbiol. 40, 795-803 (2001).

21 Pilhofer, M. et al. Characterization and evolution of cell division and cell wall synthesis genes in the bacterial phyla Verrucomicrobia, Lentisphaerae, Chlamydiae, and Planctomycetes and phylogenetic comparison with rRNA genes. J. Bacteriol. 190, 3192-3202 (2008).

22 Vicente, M., Gomez, M. \& Ayala, J. Regulation of transcription of cell division genes in the Escherichia coli dcw cluster. Cell. Mol. Life Sci. 54, 317-324 (1998).

$23 \mathrm{Bi}, \mathrm{E}$. \& Lutkenhaus, J. FtsZ ring structure associated with division in Escherichia coli. Nature 354, 161-164 (1991).

24 de Boer, P., Crossley, R. \& Rothfield, L. The essential bacterial cell-division protein FtsZ is a GTPase. Nature 359, 254-256 (1992).

25 Francis, F., Ramirez-Arcos, S., Salimnia, H., Victor, C. \& Dillon, J.-A. R. Organization and transcription of the division cell wall (dcw) cluster in Neisseria gonorrhoeae. Gene 251, 141-151 (2000).

26 Margolin, W. Themes and variations in prokaryotic cell division. FEMS Microbiol. Rev. 24, 531-548 (2000).

27 Sitnikov, D. M., Schineller, J. B. \& Baldwin, T. O. Control of cell division in Escherichia coli: Regulation of transcription of $f t S Q A$ involves both rpoS and SdiA-mediated autoinduction. Proc. Natl. Acad. Sci. USA 93, 336-341 (1996).

28 Ballesteros, M., Kusano, S., Ishihama, A. \& Vicente, M. The ftsQ1p gearbox promoter of Escherichia coli is a major sigma S-dependent promoter in the ddIB-ftsA region. Mol. Microbiol. 30, 419-430 (1998).

29 Carballès, F., Bertrand, C., Bouché, J. P. \& Cam, K. Regulation of Escherichia coli cell division genes fts $A$ and $f t s Z$ by the two-component system rcsC-rcsB. Mol. Microbiol. 34, 442-450 (1999). 
30 Pichoff, S. \& Lutkenhaus, J. Tethering the $Z$ ring to the membrane through a conserved membrane targeting sequence in FtsA. Mol. Microbiol. 55, 1722-1734 (2005).

31 Ortiz, C., Natale, P., Cueto, L. \& Vicente, M. The keepers of the ring: Regulators of FtsZ assembly. FEMS Microbiol. Rev. 40, 57-67 (2016).

32 Tamura, M. et al. RNase E maintenance of proper FtsZ/FtsA ratio required for nonfilamentous growth of Escherichia coli cells but not for colony-forming ability. J. Bacteriol. 188, 5145-5152 (2006).

33 Ye, B.-C. et al. Time-resolved transcriptome analysis of Bacillus subtilis responding to valine, glutamate, and glutamine. PLoS One 4; e7073; 10.1371/journal.pone.0007073 (2009).

34 Beuria, T. K. et al. Glutamate-induced assembly of bacterial cell division protein FtsZ. J. Biol. Chem. 278, 3735-3741 (2003).

35 Satomura, T. et al. Enhancement of glutamine utilization in Bacillus subtilis through the GInK-GInL two-component regulatory system. J. Bacteriol. 187, 4813-4821 (2005).

36 Li, L., Jiang, W. \& Lu, Y. A novel two-component system, GluR-GluK, involved in glutamate sensing and uptake in Streptomyces coelicolor. J. Bacteriol. 199, e00097-17; 10.1128/JB.00097-17 (2017).

37 Sonawane, A. M., Singh, B. \& Röhm, K.-H. The AauR-AauS two-component system regulates uptake and metabolism of acidic amino acids in Pseudomonas putida. Appl. Environ. Microbiol. 72, 6569-6577 (2006).

38 Kang, Y., Goo, E., Kim, J. \& Hwang, I. Critical role of quorum sensing-dependent glutamate metabolism in homeostatic osmolality and outer membrane vesiculation in Burkholderia glumae. Sci. Rep. 7, 44195; 10.1038/srep33195 (2017).

39 Ricard, M. \& Hirota, Y. Process of cellular division in Escherichia coli: physiological study on thermosensitive mutants defective in cell division. J. Bacteriol. 116, 314-322 (1973).

40 Sambrook, J., Fritsch, E. F. \& Maniatis, T. Molecular cloning: A laboratory manual. Second edition. (Cold Spring Harbor Laboratory Press, 1989).

41 De Lorenzo, V., Herrero, M., Jakubzik, U. \& Timmis, K. N. Mini-Tn 5 transposon derivatives for insertion mutagenesis, promoter probing, and chromosomal insertion of cloned DNA in gram-negative eubacteria. J. Bacteriol. 172, 6568-6572 (1990).

42 Kwon, Y. \& Ricke, S. Efficient amplification of multiple transposon-flanking sequences. J. Microbiol. Methods 41, 195-199 (2000).

43 Bonas, U., Stall, R. E. \& Staskawicz, B. Genetic and structural characterization of the avirulence gene avrBs3 from Xanthomonas campestris pv. vesicatoria. Mol. Gen. Genet. 218, 127-136 (1989). 
44 Figurski, D. H. \& Helinski, D. R. Replication of an origin-containing derivative of plasmid RK2 dependent on a plasmid function provided in trans. Proc. Natl. Acad. Sci. USA 76, 1648-1652 (1979).

45 Sezonov, G., Joseleau-Petit, D. \& D'Ari, R. J. J. o. b. Escherichia coli physiology in Luria-Bertani broth. J. Bacteriol. 189, 8746-8749 (2007).

46 Morris, J. K. A formaldehyde glutaraldehyde fixative of high osmolality for use in electron microscopy. J. Cell Biol. 27, 1A-149A (1965).

Figures 
(a)
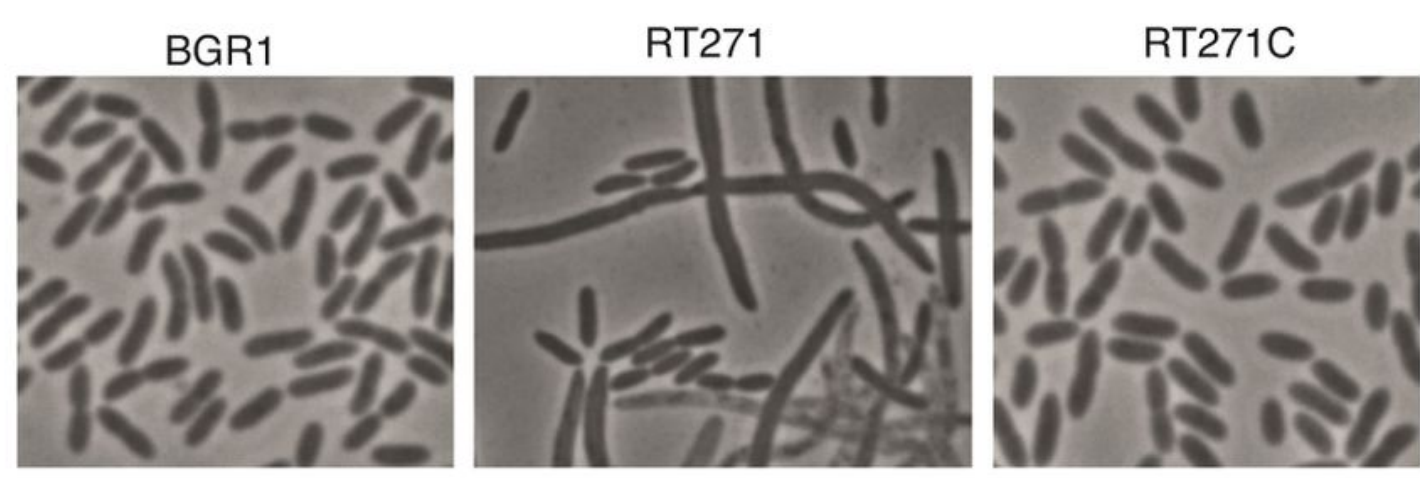

(b)
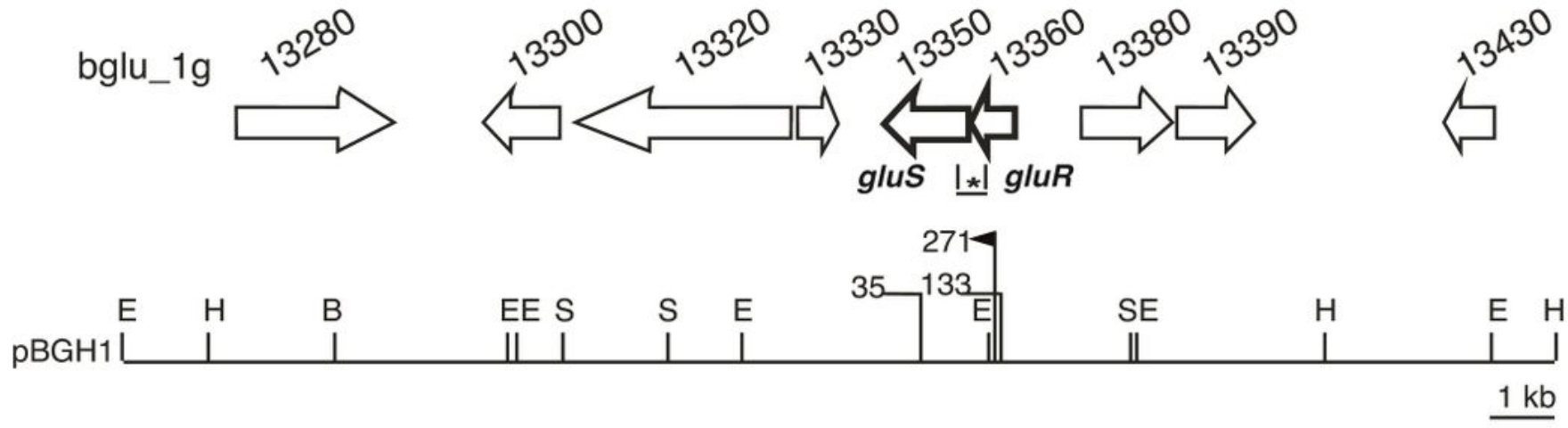

(c)

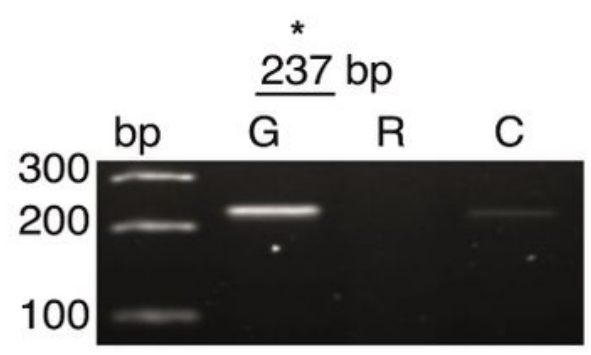

BGR1

(Wild type)

(d)

BGR1

(gluR::Tn3-gusA_133)

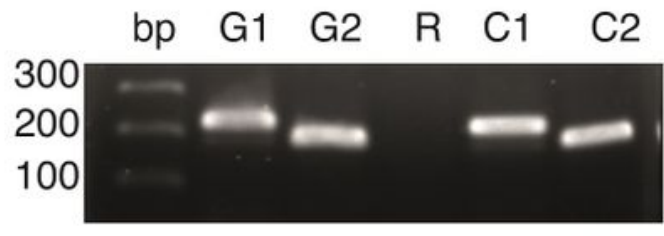

BGR1

(gluS::Tn3-gusA_35)
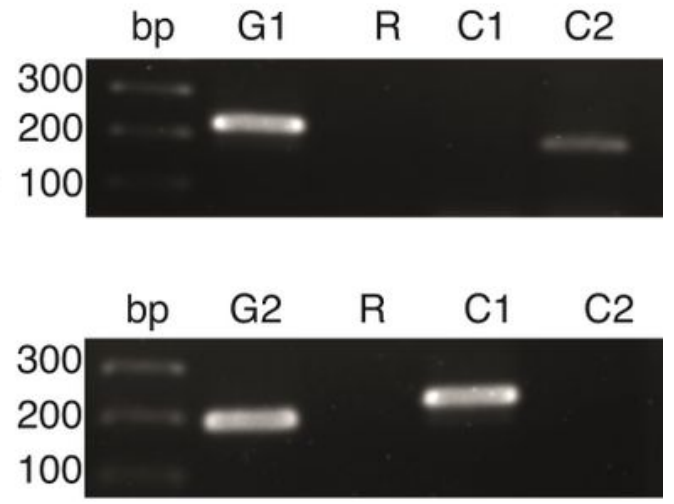

\section{Figure 1}

The GluS-GluR TCS of B. glumae BGR1. (a) Microscopic observation of the cell morphology of BGR1 (wild type), RT271 (BGR1, gluR::mini-Tn5rescue), and mutant complemented RT271C (BGR1, gluR::miniTn5rescue carrying pBGH1) strains in LB medium. (b) Organization scheme of the GluS sensor kinase and GluR response regulator in $\mathrm{pBGH} 1$. Vertical bars above the restriction map indicate the position of the Tn5 (271) and Tn3-gusA insertions (35 and 133). E, EcoRl; H, HindIIl; B, BamHl; S, Sacl. (c) RT-PCR 
analysis showing that gluS and gluR genes are co-transcribed in BGR1. Primers were designed to amplify a $237 \mathrm{bp} \mathrm{(*)}$ product encompassing the gluR and gluS genes in the wild type. Lane G, PCR product using genomic DNA as a template; Lane R, PCR product using RNA as a template; Lane C, PCR product using cDNA as a template. (d) No polar effect resulted from Tn3-gusA insertion. Lane bp, marker; Lane G1, PCR product from gluR chromosomal DNA as a template; Lane G2, PCR product from gluS chromosomal DNA as a template; Lane R, PCR product from total RNA as a template; Lane C1, PCR product from gluR CDNA as a template; Lane $\mathrm{C} 2$, PCR product from gluS cDNA as a template. Full gel images are presented in Supplementary Fig. S4 and S5.
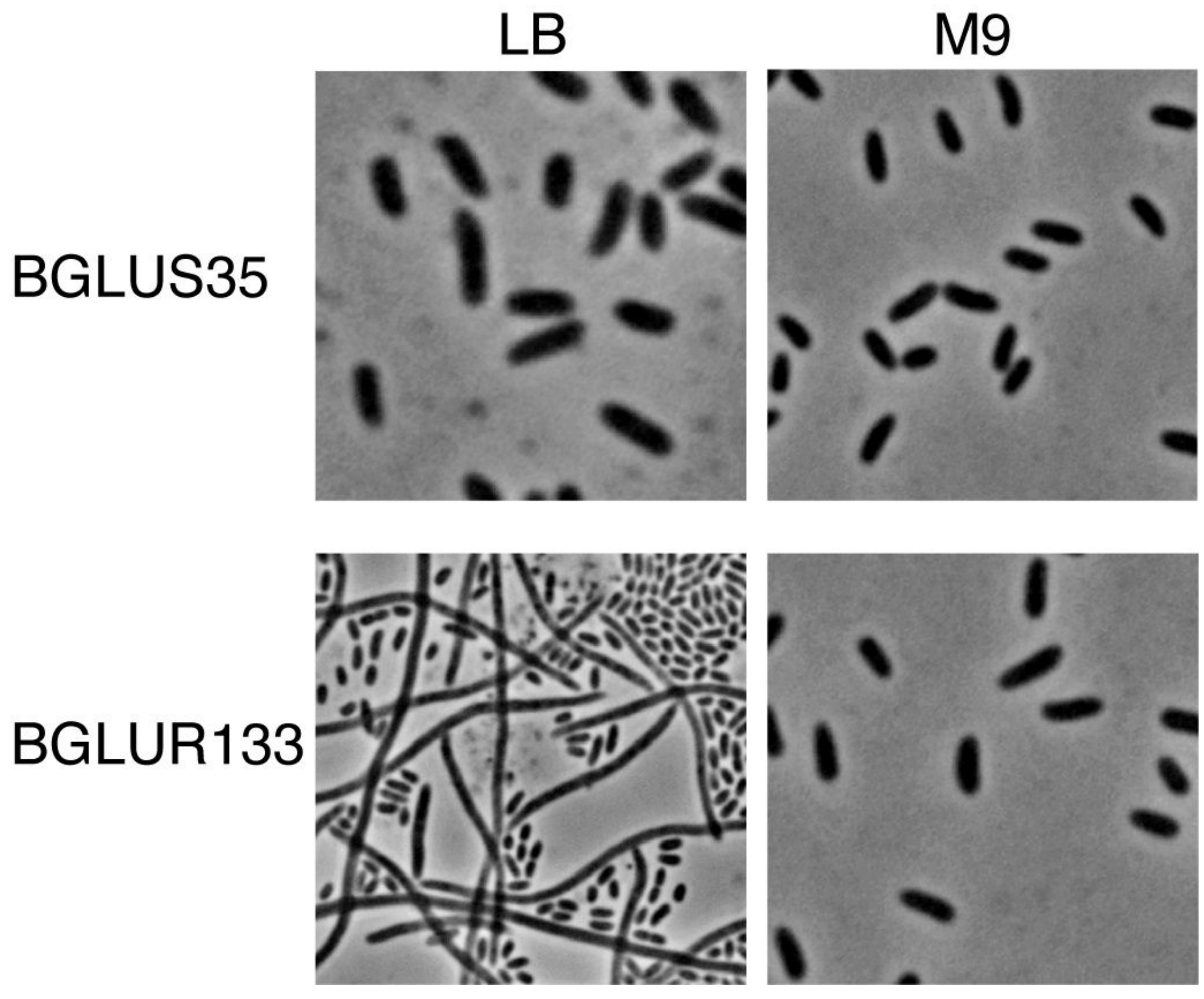

\section{Figure 2}

Tn3-gusA mutations in gluR resulted in nutrient-dependent cell filamentation. In LB medium, the gluR mutant BGLUR133 formed filamentous cells, but a normal rod-shaped cell morphology was observed in M9 minimal medium. No morphological defects were observed in the gluS mutant BGLUS35 in the different culture media. 
(b)
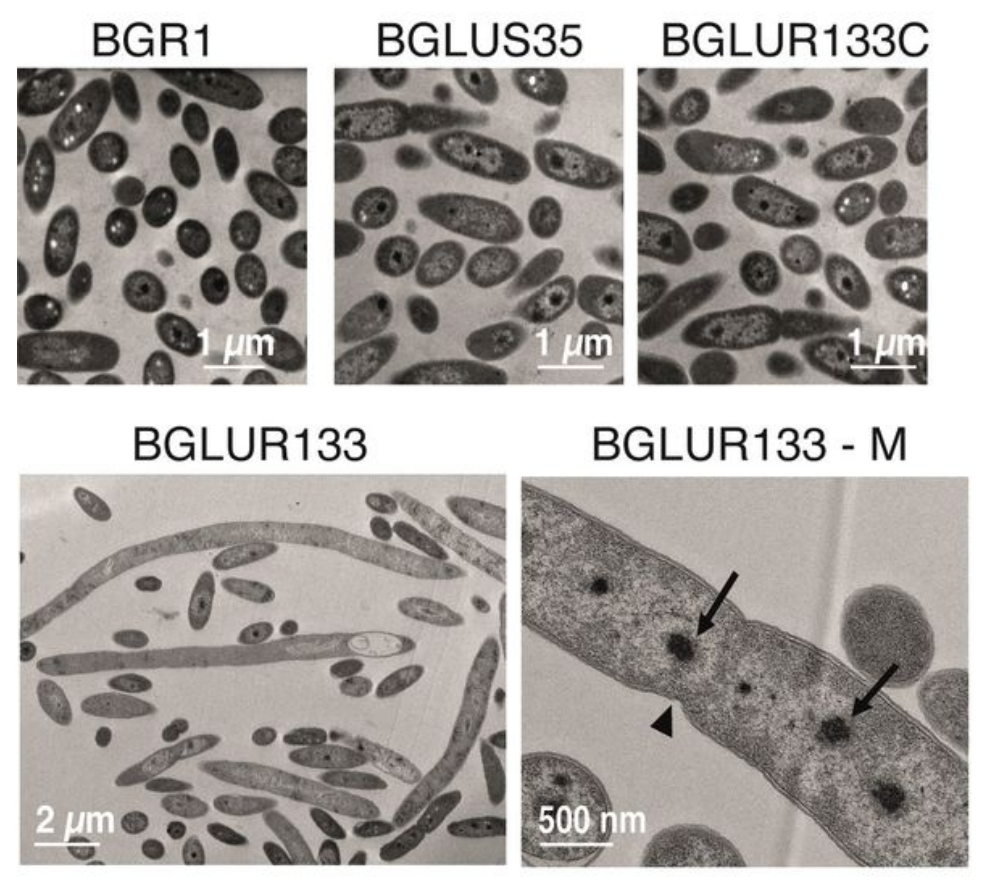

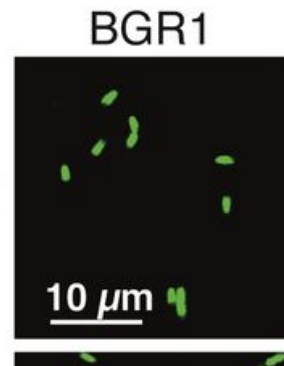

$12 \mathrm{~h}$
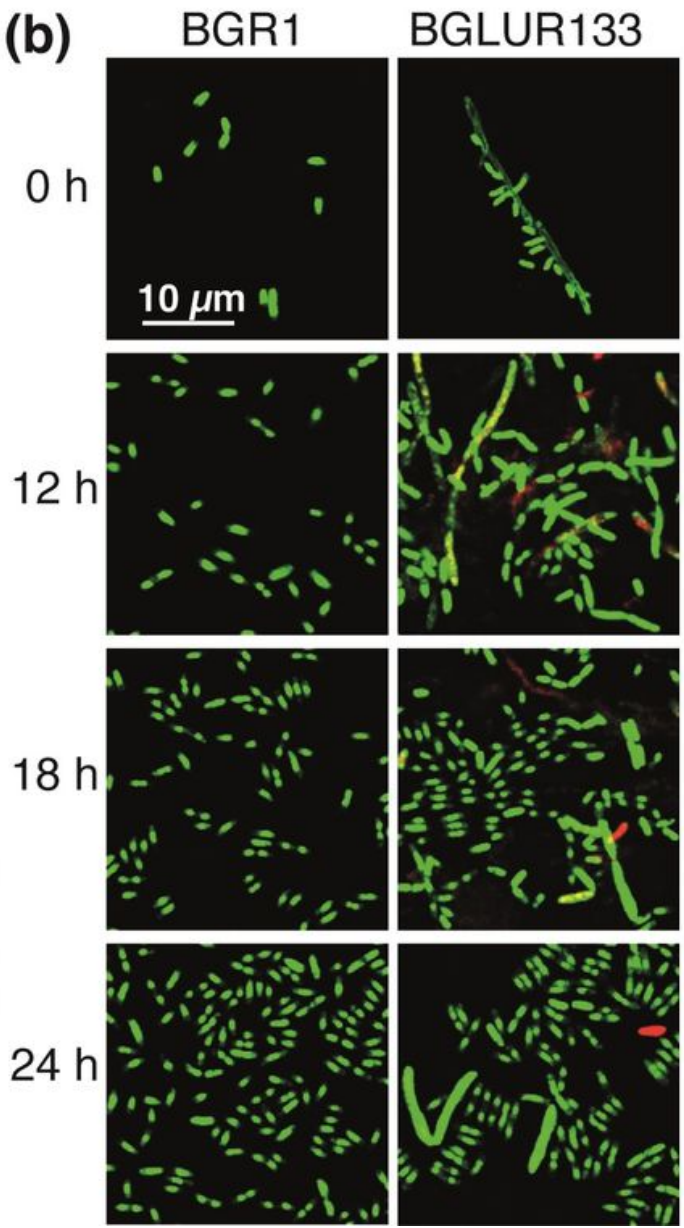
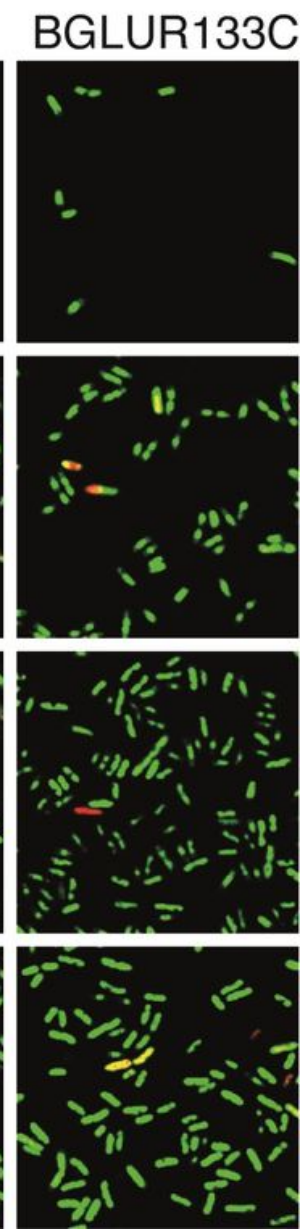

Figure 3

The gluR mutant forms a heterogeneous population of viable filamentous and normal rod-shaped cells. (a) The indicated bacterial strains were grown to early stationary phase, and the morphological phenotypes of ultrathin sections were observed by TEM. BGLUR133-M shows that the filamentous cells formed by the gluR mutant contained multiple nuclei (arrows) with indents (arrowhead) along the cell wall, symbolizing failed septum formation. (b) Cell viability of the wild type, BGLUR133, and complemented BGLUR133C strains assessed by combination staining with propidium iodide (PI) and SYTO 9 green. Fluorescence images were obtained by confocal laser scanning microscopy. Dead cells stained with PI are red, and SYTO 9-stained viable cells are green. 
(a)

bglu_1g

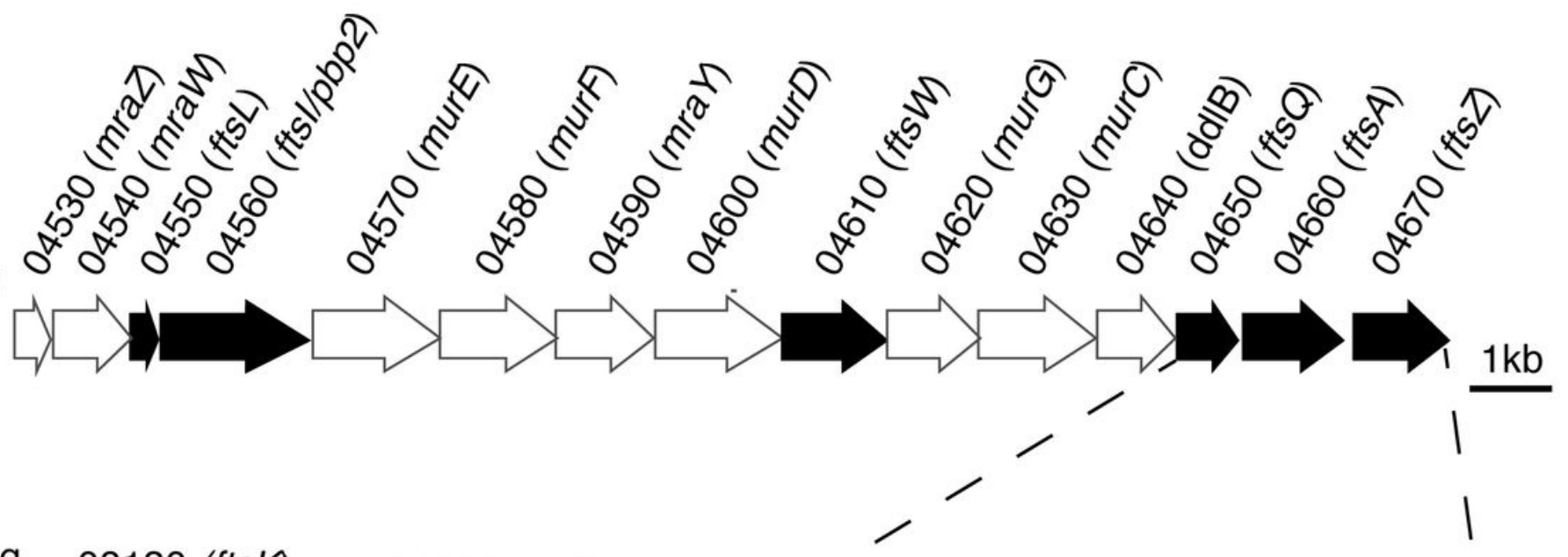

(b)
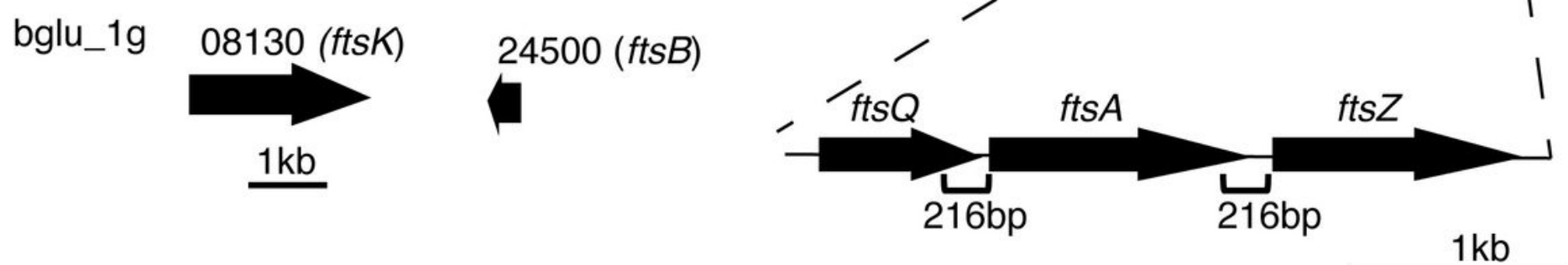

(c)

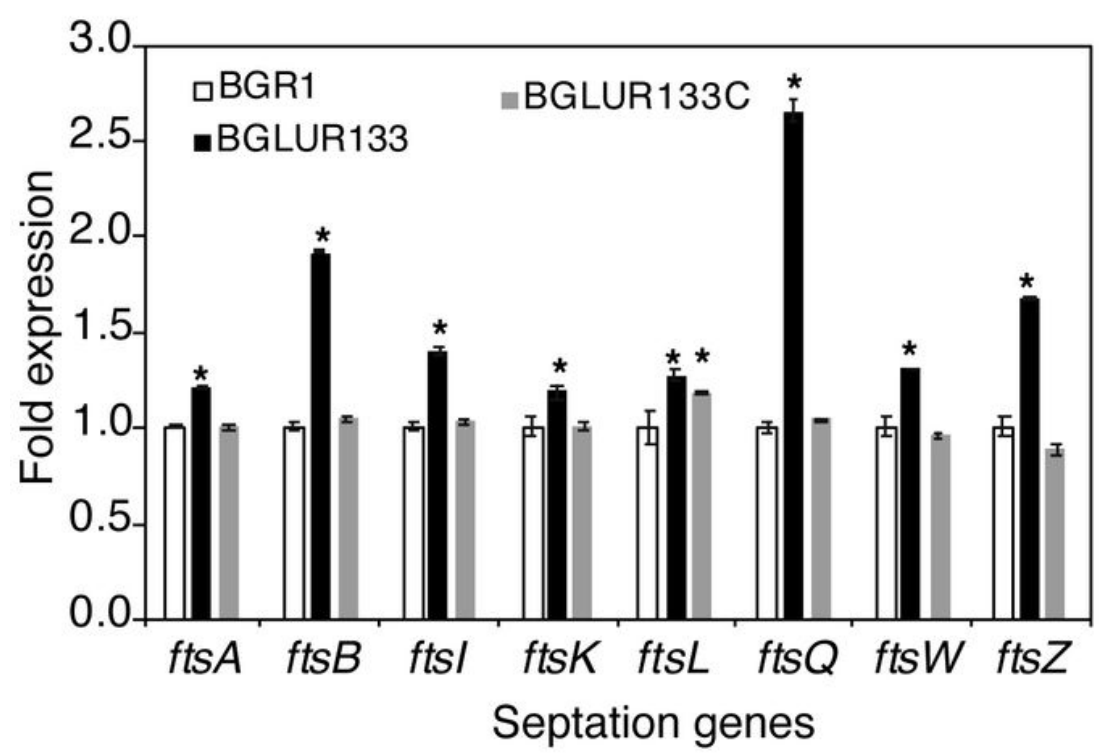

(d)

$$
\begin{aligned}
& -+++\quad+++ \text { GluR-His } \\
& ++++++++ \text { labeled target } \\
& -\quad+\quad-\quad-\quad+\quad \text { - unlabeled target } \\
& \text { - } \quad-\quad+\quad-\quad-\quad+\quad+\text { unlabeled katE }
\end{aligned}
$$
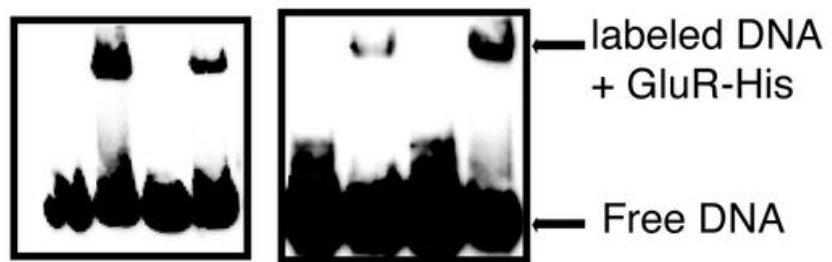

\section{Figure 4}

GluR represses cell division and septation genes in B. glumae. (a) Genetic organization of the dcw cluster in BGR1. Dark arrows represent genes involved in septation during cell division, and light arrows are genes involved in cell-wall synthesis or with no function. The section below the gene map indicates the positions and size of the respective putative promoters in this study. (b) Gene maps of additional celldivision genes outside the dcw cluster. (c) Expression levels of eight cell division genes in the wild type (BGR1), gluR mutant, and complemented BGLUR133C strains compared by qRT-PCR. mRNA levels were normalized to $16 \mathrm{~S}$ rRNA, and the fold expressions are relative to those of the wild type. Data are means \pm standard error (SE) of triplicates; statistical analysis was performed by one-way ANOVA/Tukey's 
correlation for multiple comparisons. *, $p<0.05 ;(F(48,71)=1536.273 ; p=0.00)$. (d) Electrophoretic mobility shift assay (EMSA) showed direct control of ftsA and ftsZ by GluR-His binding to the respective putative promoter regions; $0.75 \mu \mathrm{M}$ GluR-His, $1 \mathrm{nM}$ labeled target DNA, $1 \mathrm{nM}$ unlabeled katE promoter DNA, and $20 \mathrm{nM}$ unlabeled target promoter DNA were used for EMSA. Full blot images with multiple contrasts are shown in Supplementary Fig. S6.

\section{(a)}

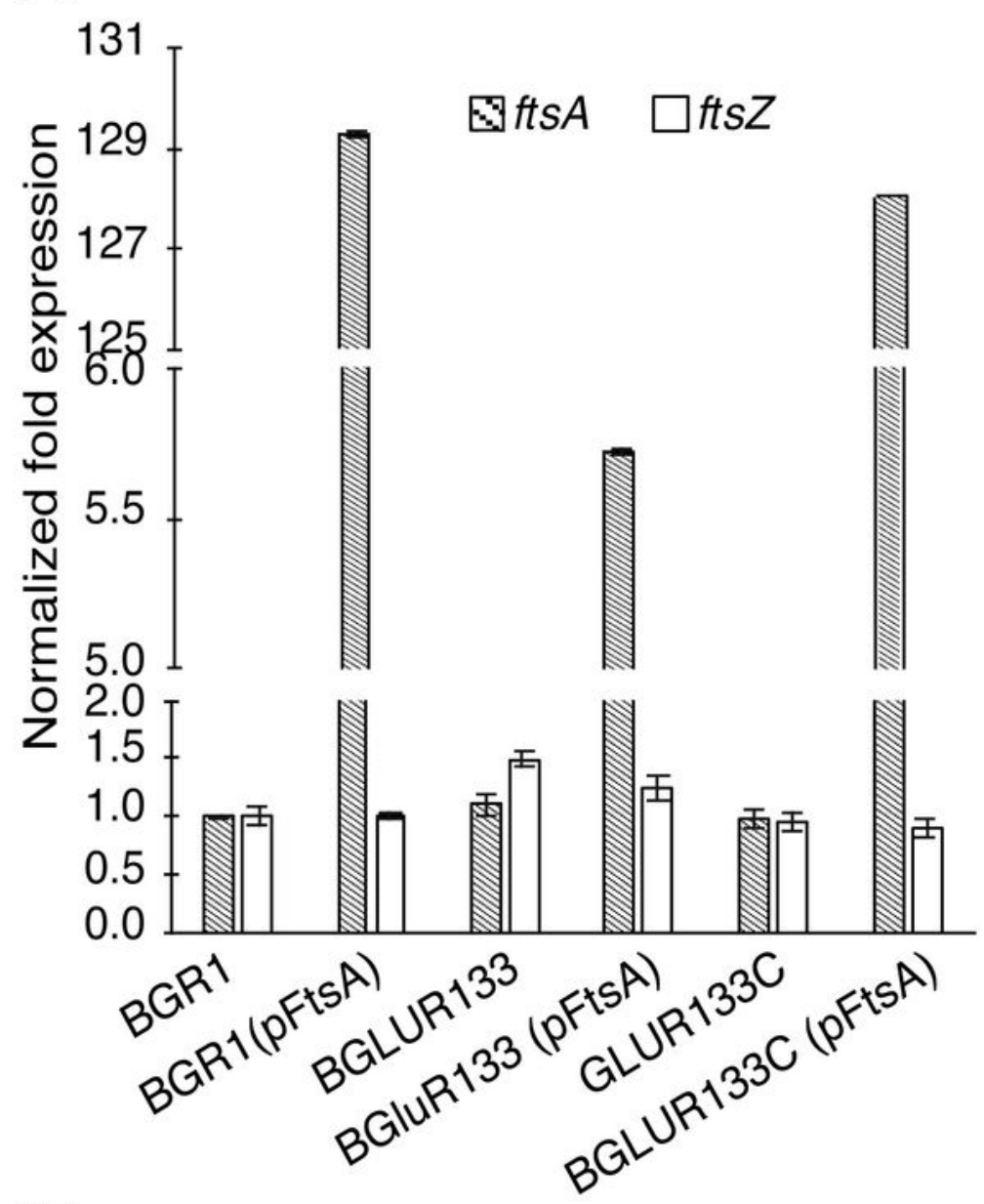

(b)

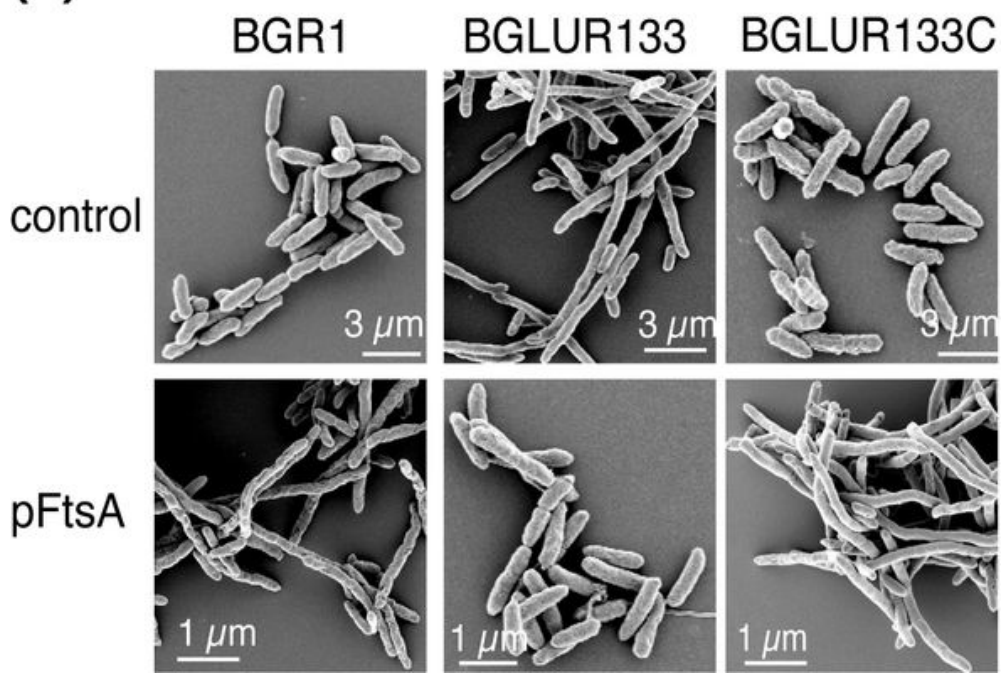

Figure 5 
GluR maintains the molar ratio of ftsZ to ftsA to ensure normal cell division. FtsA was constitutively expressed to counteract ftsZ in the wild type (BGR1), BGLUR133, and BGLUR133C strains. (a) mRNA levels were quantified by qRT-PCR and are shown as normalized fold expression values. Data are means \pm standard error (SE) of triplicates. (b) Bacterial strains cultured to early stationary phase were visualized using a Carl Zeiss $\mathrm{GmbH}$ Auriga microscope. pFtsA represents constitutive expression of $\mathrm{ftsA}$ in the indicated bacterial strains.

\section{BGR1}
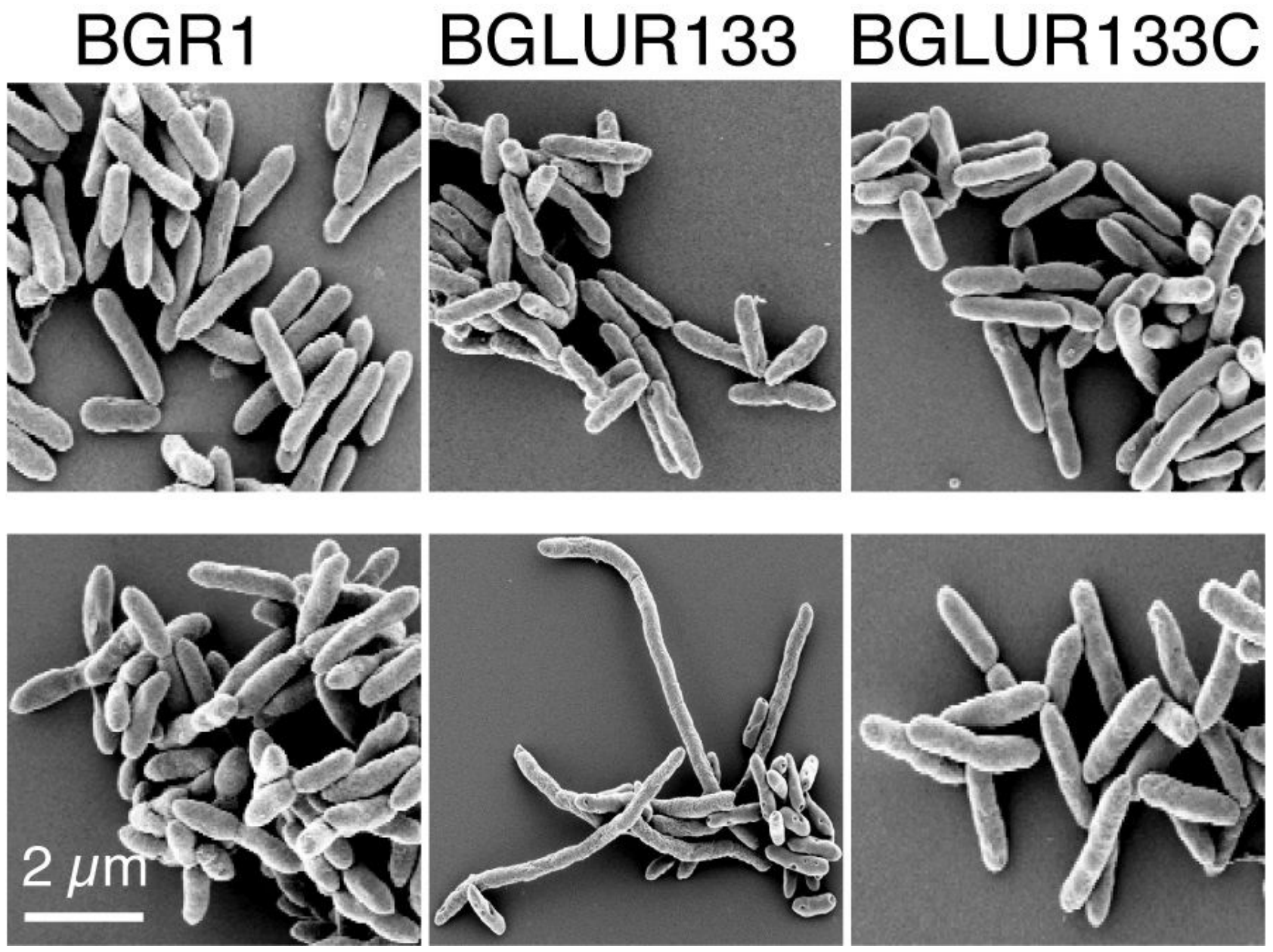

Figure 6

Extracellular amino acids promote filamentation in response to GluR mutation. The indicated bacterial strains were cultured overnight in M9 minimal medium with or without $10 \%$ casamino acids (CA), processed for SEM analysis, and their morphology observed using a Carl Zeiss GmbH Auriga microscope. 
(a)

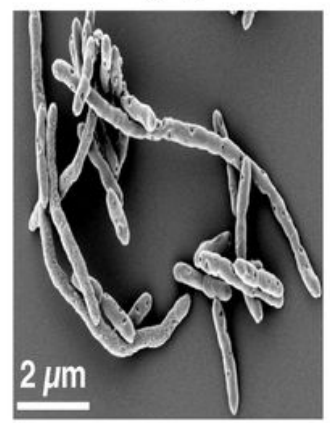

(e)
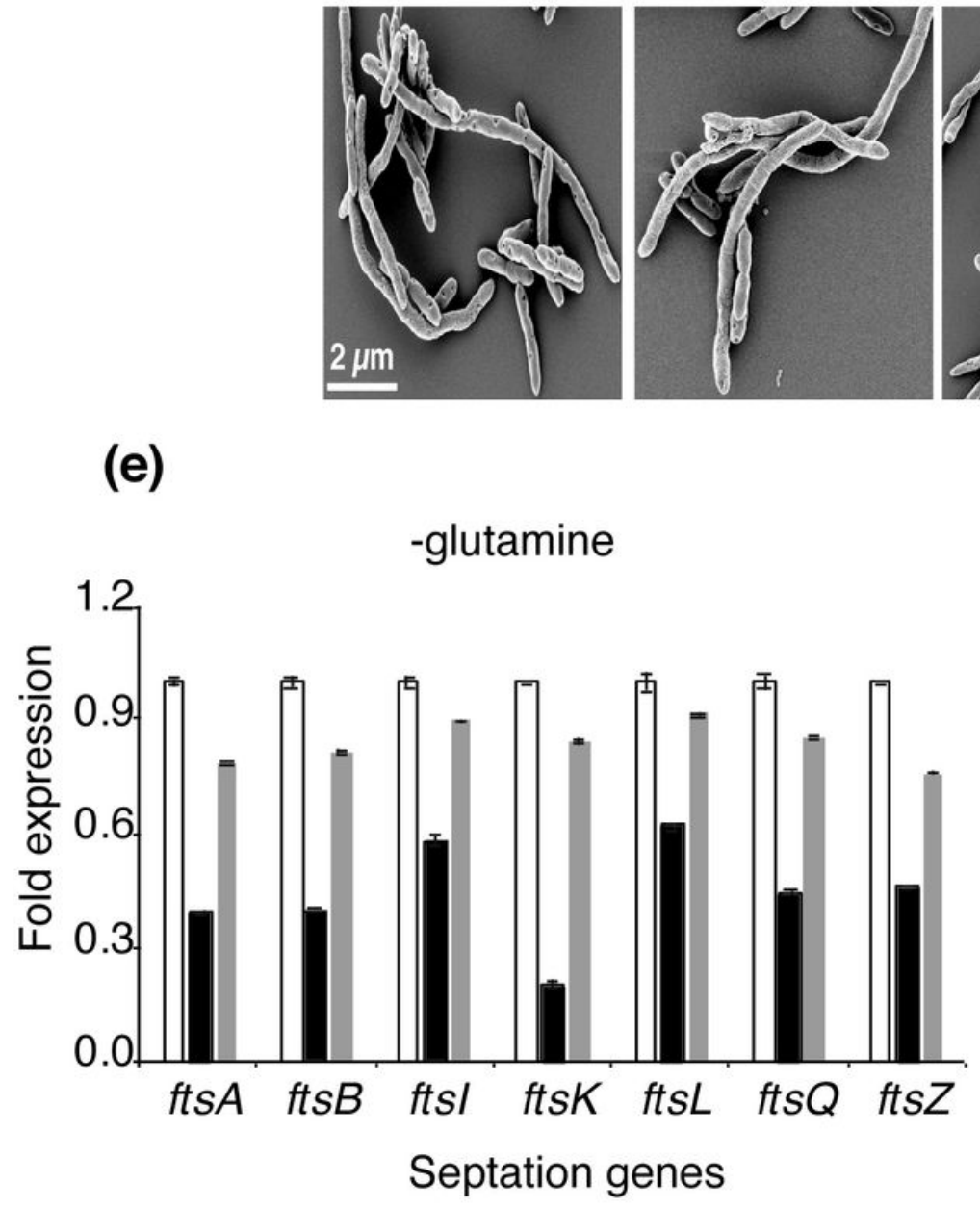

(c)

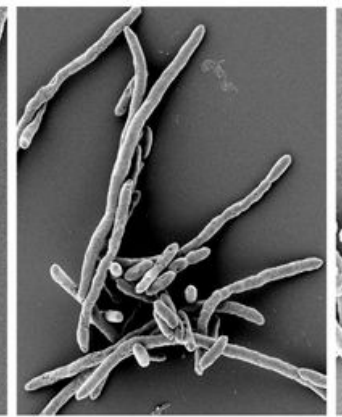

(f)

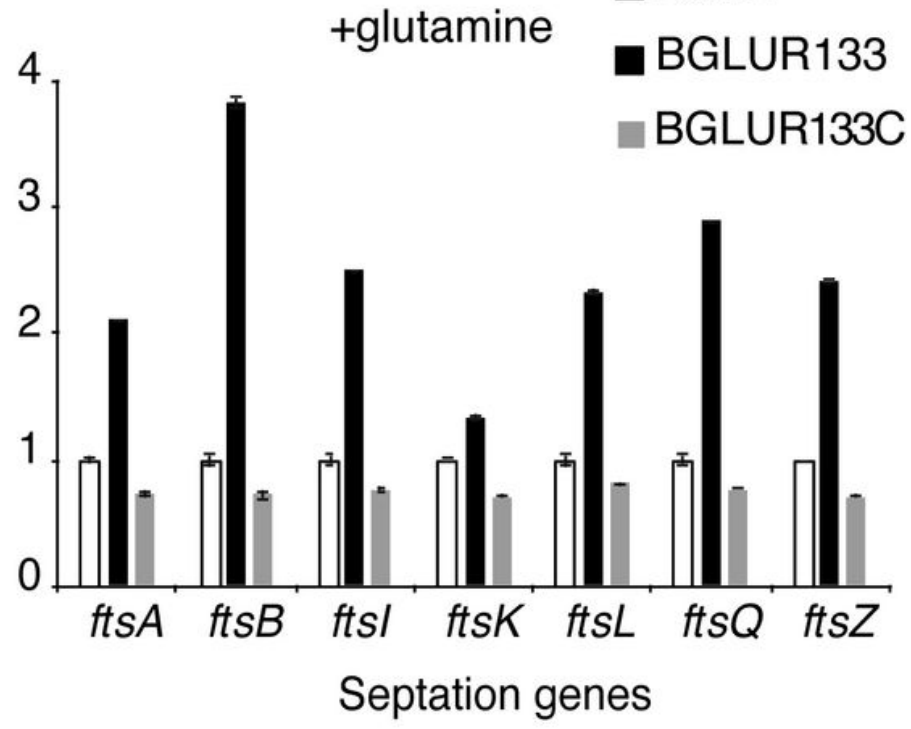

Figure 7

Extracellular glutamine and glutamate are required for GluR-mediated cell division. In an amino acid-rich M9 minimal medium, the gluR mutant BGLUR133 formed filamentous cells in (a) glutamine, (b) glutamate, and (c) several amino acids produced from glutamine (serine, alanine, proline, aspartate, and asparagine). (d) Removing glutamine and the respective metabolites restored normal cell division in the presence of the remaining 13 amino acids (arginine, cysteine, glycine, histidine, isoleucine, leucine, lysine, methionine, phenylalanine, threonine, tryptophan, tyrosine, and valine). (e-f) Differences in the expression levels of septation genes in plain M9 (e) and glutamine-rich M9 minimal medium (f), analyzed by qRTPCR using the wild-type BGR1 as the baseline. Data are means \pm standard error (SE) of triplicates. 

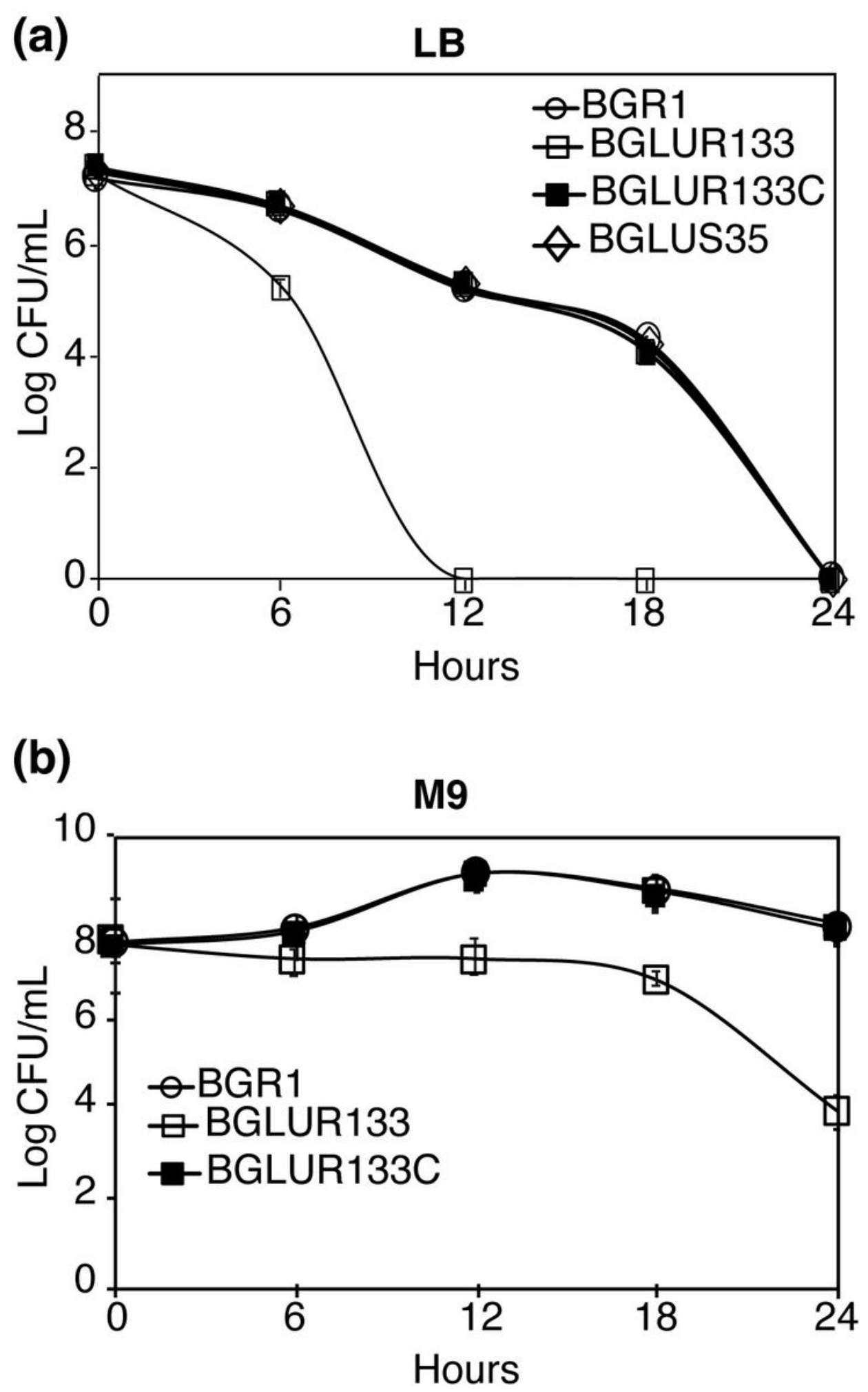

Figure 8

Exponential population decline at $420 \mathrm{C}$ as a result of mutations in GluR. At 6 hour intervals, the indicated strains' population densities in LB medium (a) and M9 medium (b), were quantified by CFU counting and the results expressed as log $\mathrm{CFU} / \mathrm{mL}$. Data are means \pm standard error (SE) of triplicates.

\section{Supplementary Files}


This is a list of supplementary files associated with this preprint. Click to download.

- Supplementarylnformation.pdf 